\title{
Osteoporosis Treatment with New Osteogenic Factors
}

\author{
Masayoshi Yamaguchi* \\ Department of Hematology and Medical Oncology, Emory University School of Medicine, Atlanta, Georgia, USA
}

\begin{abstract}
Bone homeostasis is maintained through a delicate balance between osteoblastic bone formation and osteoclastic bone resorption. Bone loss may be due to decreased osteoblastic bone formation and increased osteoclastic bone resorption. Osteoporosis is induced with its accompanying decrease in bone mass. Nutrition and functional food factors may play a role in the prevention of bone loss. This is worthy of notice in the treatment of osteoporsis. It has been shown that functional food factors including zinc, genistein and vitamin $\mathrm{K}_{2}$ (menaquinone-7) have potential osteogenic effects in vitro and in vivo. These factors have been shown to have stimulatory effects on osteoblastic bone formation and suppressive effects on osteoclastic bone resorption. Moreover, the osteogenic effects of genistein, menaquinone-7, and vitamin $D_{3}$ have been found to be synergistically enhanced with combination of zinc, which plays an essential role in protein synthesis at translational process and gene expression related to zinc finger transcription factors. Intake with their combination has been shown to have potential effects in the treatment of bone loss in animal models of osteoporosis and human subjects. Supplemental intake with these compositions may have potential effects on osteoporosis treatment.
\end{abstract}

Keywords: Osteoporosis; Osteoblastic bone formation; Osteoclastic bone resorption; Zinc; Genistein; Vitamin $\mathrm{K}_{2}$; Menaquinone-7; Vitamin $\mathrm{D}_{3}$

\section{Introduction}

Bone homeostasis is maintained through a delicate balance between osteoblastic bone formation and osteoclastic bone resorption. Numerous pathological processes have the capacity to disrupt this equilibrium leading to conditions where the rate of bone resorption outpaces the rate of bone formation leading to osteoporosis, a devastating bone disease that is widely recognized as a major public health threat $[1,2]$. Osteoporosis is induced with decrease in bone mass. Postmenopausal osteoporosis, a consequence of ovarian hormone deficiency, is the archetypal osteoporotic condition in women after menopause and leads to bone destruction though complex and diverse metabolic and biochemical changes. The most dramatic expression of the disease is represented by bone fractures.

Reduction in bone mass is induced due to decreased osteoblactic bone formation and increased osteoclastic bone resorption. Malnutrition or undernutrition is often observed in the elderly, and it appears to be more intense in patients with bone fracture than in the general aging population [3]. Deficiency in both micronutrients and macronutrients appears to be strongly implicated in the pathogenesis and the consequences of bone fracture in the osteoporotic elderly. Nutritional and functional food factors may have potential effects to delay degenerative bone disorders such as osteoporosis.

There is growing evidence that nutritional and functional food factors regulate bone homeostasis and have restorative effects on bone loss with various pathophysiologic conditions [4]. Zinc, genistein, and vitamin $\mathrm{K}_{2}$ (menaquinone-7) has been shown to have osteogenic effects and these factors play a role in the prevention of bone loss in animal model for osteoporosis and human subjects $[4,5]$. Interestingly, their combination with zinc has been found to have potential synergistic effects on osteogenesis [4,5]. This review will discuss new development on osteoporosis treatment with the combination of biomedical food factors.

\section{Synergistic Effects of Zinc and Genistein on Osteogenesis}

\section{Role of zinc in bone homeostasis and osteoporosis}

Zinc plays a pivotal role as zinc-finger protein: Bone homeostasis is regulated by the functions of osteoblasts and osteoclasts, which are major cells in bone tissues [6,7]. Osteoclasts, which develop from hematopoietic progenitors, are recruited to the site and excavate the calcified matrix. In the physiologic process of bone turnover, a resorptive stimulus firstly triggers recruitment of osteoclasts to a site on the bone surface. During the initiation phase of bone resorption, osteoblasts arising from local mesenchymal stem cells assemble at the bottom of the cavity and bone formation begins. After the resorbed lacunar pit is filled with new osteoid, osteoblasts become flatter and less active, with the final newly remodeled bone surface lined by flat lining cells. Remodeling of cancellous bone begins with the retraction of lining cells that cover the bone surface $[6,7]$. Bone acts as major storage site for growth factors, which are produced by osteoblasts, diffuse into newly deposited osteoid and are stored in the bone matrix including isulin-like growth factors (IGF- I and II), transforming growth factor- $\beta 1$ (TGF- $\beta 1$ ), platelet-derived growth factor (PDGF), or bone morphologic proteins (BMPs) [8]. These bone-derived factors, which can be liberated during subsequent periods of bone resorption, act in an autocrine, paracrine, or delayed paracrine fashion in the local microenvironment of the bone surface. This process of bone remodeling to make bone is complexity with respect to interactions along the remodeling sequence by systemic influences (hormones), stress action (physical activity/weight bearing), growth factors and cytokines which are produced by the bone cells and came from nearby cells present in the marrow tissues.

*Corresponding author: Masayosh Yamaguchi, Department of Hematology and Medical Oncology, Emory University School of Medicine, Atlanta, Georgia, USA, E-mail: yamamasa1155@yahoo.co.jp

Received July 19, 2013; Accepted August 12, 2013; Published August 14, 2013

Citation: Yamaguchi M (2013) Osteoporosis Treatment with New Osteogenic Factors. J Mol Genet Med 7: 66. doi:10.4172/1747-0862.1000066

Copyright: () 2013 Yamaguchi M. This is an open-access article distributed under the terms of the Creative Commons Attribution License, which permits unrestricted use, distribution, and reproduction in any medium, provided the original author and source are credited 
Zinc plays an important role in the regulation of bone homeostasis. Zinc finger transcription factors, which are zinc-binding protein, play a pivotal role in differentiation of osteoblastic cells and osteoclastic cells. Zinc transporter has been shown to locate in osteoblastic cells [9] and osteoclastic cells [10]. Zinc transporter may be a role in the uptake, intracellular sequestration or efflux of zinc. A novel zinc fingercontaining transcription factor, called Osterix (Osx), has been found in osteoblastic cells [11]. Osx is required for osteoblast differentiation and bone formation and it acts downstream of Runx2/Cbfa1 [12]. Casinteracting zinc finger protein (CIZ) has been found to be a novel type inhibitor of bone morphogenetic protein (BMP)/Smad signaling in the modulation of BMP2-induced osteoblastic cell differentiation [13]. Moreover, Schnurri-3 (Shn3) is an essential regulator of adult bone formation [14]. A novel TIZ (TRAF6-inhibitory zinc finger protein) has been shown to inhibit osteoclastogenesis and the function of tumor necrosis factor receptor-associated factor 6 [15]. Nutritional zinc state may influence on function of zinc finger proteins.

Zinc is required for the growth, development, and maintenance of healthy bones. The retardation of bone growth is a common finding in various conditions associated with zinc deficiency $[16,17]$. Skeleton contains a large proportion of the total body burden of zinc. Bone zinc has been shown to concentrate in the layer of osteoid prior to calcification [18]. Zinc deficiency is associated with many kinds of skeletal abnormalities in fetal and postnatal development. Nutritional zinc may play a physiologically important role in bone growth.

Osteoporotic patients have been shown to have lower levels of skeletal zinc than control. In postmenopausal women, urinary zinc has been suggested as a marker of bone resorption, since women with osteoporosis excrete over than $800 \mu \mathrm{g}$ zinc per g creatinine in urine [19].

Thus, zinc plays a pivotal role in the regulation of bone homeostasis.

Zinc stimulates osteoblastic bone formation: Zinc stimulates bone formation in in vitro and in vivo [20,21]. Bone calcium content, alkaline phosphatase activity and collagen content have been shown to increase after culture with zinc, and these increases were depressed in the presence of an inhibitor of protein synthesis. Zinc has direct stimulatory effects on bone mineralization in vitro, and that bone protein synthesis is a necessary component of this response [22]. Endogenous zinc in the bone tissues has been shown to play an essential role in bone protein synthesis by using dipicolinate, a chelator of zinc [23].

Zinc has been shown to stimulate differentiation and proliferation in osteoblastic MC3T3-E1 cells [24,25]. The stimulatory effect of zinc on protein synthesis in osteoblastic MC3T3-E1 cells [26] in vitro has been demonstrated using $\left[{ }^{3} \mathrm{H}\right]$-leucine. The activity of $\left[{ }^{3} \mathrm{H}\right]$-leucyltRNA synthetase in the $105,000 \mathrm{~g}$ supernatant fraction (cytosol) of the bone homogenate was significantly increased about twofold after culture with zinc $\left(10^{-4} \mathrm{M}\right)[22,26]$. Zinc is found to activate $\left[{ }^{3} \mathrm{H}\right]$-leucyltRNA synthetase in the homogenate of osteoblastic cells [26]. Zinc has been shown to have direct stimulatory effects on protein synthesis at translational process. Endogenous zinc in the bone tissues is needed the stimulation of protein synthesis at the translational process in osteoblastic cells.

Zinc has been shown to increase various protein components including osteocalcin, IGF-I, or TGF- $\beta 1$ in osteoblastic MC3T3-E1 cells [27]. The stimulatory effects of IGF-I on alkaline phosphatase activity, protein, DNA, and cell number in the cells were markedly enhanced in the presence of zinc sulfate $\left(10^{-5} \mathrm{M}\right)$ [28]. Such an effect was not seen in case of both insulin and zinc. The enhancing effect of zinc on the effect of IGF-I may be mediated through signaling pathway of protein kinase $\mathrm{C}$ and protein phosphatase in osteoblastic cells [28]. Zinc increases protein tyrosine phosphatase activity in osteoblastic cells [29]. The effect of IGF-I in increasing this enzyme activity was enhanced after culture with zinc sulfate [29]. Zinc modulates anabolic effect of IGF-I on protein tyrosine phosphatase activity and cell proliferation.

Zinc has also been to stimulate DNA synthesis in the homogenate of osteoblastic cells in vitro [30]. Moreover, zinc has been found to stimulate the mRNA expression of Runx2, a transcription factor, which is related to the differentiation from mesenchymal stem cells to preosteoblastic cells [31].

Thus, zinc stimulates cell differentiation, cell proliferation, and mineralization in osteoblasts, thereby promoting bone formation.

Zinc suppresses osteoclastic bone resorption: Zinc has a suppressive effect on bone resorption in tissue culture in vitro [32]. Calvaria were removed from weanling rats and cultured for periods of up to 48 hours in a medium containing various bone-resorbing

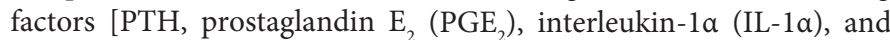
lipopolysacharide (LPS)]. Culture with these factors caused a significant decrease in bone calcium content. Such decreases were completely inhibited in the presence of zinc $\left(10^{-6}\right.$ to $\left.10^{-4} \mathrm{M}\right)$. Also, zinc suppressed PTH- or IL-1 $\alpha$-induced increases in medium glucose consumpion and lactic acid production by bone tissues [32]. Thus, zinc has been demonstrated to have suppressive effects on bone resorption in bone tissue culture system in vitro.

Osteoclasts, bone-resorbing cells, are formed by differentiation of bone marrow cells. Zinc has suppressive effects on osteoclast-like cell formation in mouse marrow culture in vitro [33,34]. Presence of 1 , 25-dihydroxyvitamin $\mathrm{D}_{3}\left[1,25(\mathrm{OH})_{2} \mathrm{D}_{3}\right]$, PTH, IL-1 $\alpha$, or $\mathrm{PGE}_{2}$ induced a remarkable increase in osteoclast-like multinucleated cells [33]. These increases were suppressed in the presence of zinc [33]. Suppressive effects of zinc were equal in comparison with the effect of other antibone resorbing agents (calcitonin, 17 $\beta$-estradiol, or acetazolamide) on osteoclast-like cell formation in mouse bone marrow culture [33]. In addition, culture with zinc caused apoptotic cell death of mature osteoclast-like cells isolated from rat femoral tissues [34]. Zinc has suppressive effects on osteoclastogenesis and osteoclastic cell death.

Stimulatory effects of PTH on osteoclast-like cell formation were weakened (about 50\%) in the presence of $\mathrm{Ca}^{2+}$ chelator or dibucaine, a regulatory factor of intracellular $\mathrm{Ca}^{2+}$ signaling [35]. Phorbol 12-myristate 13-acetate (PMA), an activator of protein kinase C, stimulated osteoclast-like cell formation [35]. This effect of PMA was inhibited in the presence of zinc [36]. These findings support the view that zinc inhibits PTH-stimulated osteoclast-like cell formation mediated through $\mathrm{Ca}^{2+}$-dependent activation of protein kinase $\mathrm{C}$.

The receptor activator of NF- $\kappa B$ ligand (RANKL) plays a pivotal role in the development of osteoclasts from preosteoclasts $[37,38]$. RANKL is secreted from osteoblasts. RANKL is a member of the tumor necrosis factor (TNF) superfamily, which was originally identified as T-cell-derived immunomodulatory cytokines [37]. RANKL/RANK pathway is essential for osteoclast differentiation [37,38]. Expression of RANKL is increased in osteoblastic cells and bone marrow stromal cells in response to osteotropic factors such as PTH, $1,25(\mathrm{OH})_{2} \mathrm{D}_{3}$, or $\mathrm{PGE}_{2}$. The effect of RANKL is abrogated by osteoprotegerin (OPG), a natural antagonist of RANKL, $[37,38]$. OPG is produced in osteoblastic 
cells. TNF receptor-associated factor (TRAF) family proteins are adaptor molecules. TRAFs bind to the membrane-proximal region of RANK and IL-1R-associated kinase and are critically involved in the intracellular signal transduction including NF- $\kappa \mathrm{B}$ and mitogenactivated protein kinase (MAPK) activation $[37,38]$.

Zinc has been shown to have suppressive effects on RANKL-induced osteoclast-like cell formation in mouse marrow culture in the presence of M-CSF [39]. Also, zinc inhibited TNF- $\alpha$-induced osteoclastogenesis [39]. Suppressive effects of zinc on osteoclastogenesis may be involved in inhibitory effect on RANKL stimulation. Culture with zinc has been shown to have stimulatory effects on the expression of OPG mRNA in osteoblastic cells [31]. The mechanism by which zinc suppresses osteoclastogenesis may also be related to production of OPG in osteoblastic cells.

As described above, zinc has been shown to have stimulatory effects on osteoblastic bone resorption and suppressive effects on osteoclastic bone resorption, thereby increasing bone mass. Zinc plays a pivotal in the regulation of osteoblasts and osteoclasts. This may be involved in many zinc-related proteins, which are identified in bone cells as shown in Table 1.

Zinc supplementation prevents bone loss in various pathophysilogical states: Zinc has been shown to have preventive effects on bone loss in various pathophysiologic states. Fracture healing can be envisioned as involving five distinguishable processes, including the immediate response to injury, intramembranous bone formation, chondrogenesis, endochondral bone formation leading to the reestablishment of load bearing function, and bone remodeling [40]. These processes may occur simultaneously during fracture repair. During fracture healing, a number of growth factors, cytokines, and their cognate receptors are present at elevated levels in and around the fracture site [40].

The role of zinc in fracture healing has been examined using by the diaphyseal tissues obtained at 7 or 14 days after the fracture of femoral diaphysis of rats [41,42]. Oral administration of zinc acexamate $(100$ $\mathrm{mg} \mathrm{Zn} / \mathrm{kg}$ ) for 28 days prevented the decrease in zinc and other bone components in the femoral-diaphyseal tissues of rats with fracture healing [43]. Zinc supplementation may have a role in the promotion of the healing of femoral fracture.

Zinc plays a role in the deterioration of bone metabolism with

Table 1: Zinc-related protein molecules in bone cells.

\begin{tabular}{|l|c|c|}
\hline Proteins & Bone cells & References \\
\hline Zinc finger transcription factors & & \\
$\quad$ Osterix & Osteoblast & 11 \\
Cas-interacting zinc finger protein (CIZ) & Osteoblast & 13 \\
Schnurri-3 (Shn3) & Osteoblast & 14 \\
TRAF6-inhibitory zinc finger protein & Osteoblast & 15 \\
Zinc transporter Znt5 & Osteoblast & 9 \\
Zinc transporter ZIP1 & Osteoclast & 10 \\
Alkaline phosphatase & Osteoblast & 22 \\
Aminoacyl-tRNA synthetase & Osteoblast & 24,25 \\
\hline Increase in gene expression & & \\
Runx2 & Osteoblast & 33 \\
a1 (1) collagen & Osteoblast & 69 \\
Osteocalcin & Osteoblast & 29 \\
Osteoprotegerin (OPG) & Osteoblast & 33 \\
IGF-1 & Osteoblast & 29 \\
TGF- $\beta 1$ & Osteoblast & 29 \\
Decrease in gene expression & Osteoclast & 70 \\
Caspase-3 & Osteoclast & 70 \\
Cathepsin K & Osteoclast & 70 \\
Tartrate resistant acid phosphatase &
\end{tabular}

increasing age. Zinc content in the cellular components but not the matrix is lowered in the femoral diaphysis of elderly rats (30 weeks old) as compared with that of weanling rats (3 weeks old) [44]. Bone protein synthesis was most likely deteriorated with increasing age [44]. Oral administration of zinc sulfate ( 5 to $20 \mathrm{mg} \mathrm{Zn} / \mathrm{kg}$ ) for 3 days restored the rate of $\left[{ }^{3} \mathrm{H}\right]$-leucine incorporation [44]. Bone endogenous zinc may play a physiological role in the development of bone loss with increasing age. In aging, supplementation of zinc may be important in the prevention of bone loss with aging.

Zinc content is decreased in the femoral-metaphyseal tissues of rats with skeletal unloading, which is involved in the alteration of bone metabolism [45]. Skeletal unloading induces osteopenia after immobilization, spaceflight, bedrest, or hindlimb suspension. Skeletal unloading results in an inhibition of bone formation and induces an increase in bone resorption, thereby a loss of bone mass. Animals were fed for 4 days with the unloading. Unloading induced a decrease in metaphyseal zinc content [46]. Zinc accumulation in the metaphyseal tissues after a single oral administation of zinc sulfate $(200 \mathrm{mg} \mathrm{Zn} / \mathrm{kg})$ was depressed with unloading [46].

$\beta$-Alanyl-histidinato zinc (AHZ) has been shown to have a potent effect on osteogenesis as compared with that of zinc sulfate [47]. Oral administration of AHZ has been shown to have a preventive effect on bone loss, which is caused with aging [48], inflammation [36], and ovariectomy [49].

Zinc acexamate has been found to have a potent effect on bone formation as compared with that of AHZ in vitro. Oral administration of zinc acexamate ( $25 \mathrm{mg} \mathrm{Zn} / \mathrm{kg}$ body weight) for 14 or 21 days with once daily has been found to have restorative effects on the increase in serum glucose and triglyceride levels and the reduction of bone components induced in streptozotocin-induced diabetic rats [50,51], indicating that zinc has a restorative effect on insulin-dependent diabetic conditions.

In addition, citrated zinc bisglycinate has been developed as a zinc supplement. This compound has been shown to increase bioavailability in intestinal absorption of zinc, and it is used as a zinc supplementation.

Supplemental intake with zinc, which has stimulatory effects on osteoblastic bone formation and mineralization and suppressive effects on osteoclastic bone resorption, is a useful tool in the prevention and treatment of osteoporosis.

\section{Role of genistein in bone homeostasis}

Genistein stimulates osteoblastic bone formation: Isoflavones (including daidzin, daidzein, genistein and genistein) are present in soybeans at relatively high concentrations. Daidzin or genistin are hydrolyzed to daidzein or genistein by $\beta$-glucosidase in the gastrointestinal system, respectively. The anabolic effects of genistein on bone metabolism have been firstly demonstrated in tissue culture using the femoral metaphyseal (trabecular bone) tissues obtained from elderly female rats in vitro [52]. Culture with genistein $\left(10^{-6}\right.$ or $\left.10^{-5} \mathrm{M}\right)$ has been found to induce a significant increase in bone components (calcium content, alkaline phosphatase activity and DNA content) in rat femoral metaphyseal tissues [52]. The effect of genistein in increasing bone components was equal to the stimulatory effects of $17 \beta$-estradiol, which is important anabolic hormone in bone metabolism. The effect of genistein was greater than that of genistin [52]. The effect of daizein was equal to that of genistein $\left(10^{-6}\right.$ or $\left.10^{-5} \mathrm{M}\right)$ [53]. The combination of daidzein and genistein did not have an additive effect. 
The anabolic effect of genistein on osteoblastic cells in vitro has been demonstrated [54-57]. Culture with genistein $\left(10^{-6}\right.$ or $\left.10^{-5} \mathrm{M}\right)$ or daidzein $\left(10^{-6}\right.$ or $\left.10^{-5} \mathrm{M}\right)$ caused a significant increase in protein content, alkaline phosphatase activity and DNA content in the cells [55]. The ability of genistein or daidzein to increase biochemical components in the cells was not seen in the presence of an inhibitor of protein synthesis, suggesting that the effects of isoflavone result from newly synthesized protein components [55]. The effects of $17 \beta$-estradiol in increasing protein content and alkaline phosphatase activity in osteoblastic cells were not enhanced in the presence of genistein [55]. Cellular protein content was additively increased with $17 \beta$-estradiol and daidzein, but their effects on alkaline phosphatase activity were not additively [56]. Genistein has been shown to bind to estrogen receptor $\beta$ in osteoblastic cells, and daidzein cannot bind to the receptor [53]. The effect of genistein may partly mediated through estrogen receptor $\beta$, but not $\alpha$, in osteoblastic cells. Genistein and daidzein may have stimulatory effects on the proliferation and differentiation of osteoblastic MC3T3-E1 cells.

The cellular mechanism by which isoflavones stimulate osteoblastic bone formation has been studied in relation to protein synthesis. Culture with genistein or daidzein stimulated protein synthesis in osteoblastic MC3T3-E1 cells in vitro [57]. Moreover, genistein or daidzein has been shown to increase $\left[{ }^{3} \mathrm{H}\right]$-leucyl-tRNA synthetase activity in the cytosol fraction of osteoblastic cell homogenate [57]. Genistein had a greater effect than daidzein [57]. Genistein can directly activate leucyl-tRNA synthetase, a rate-limiting enzyme in the translational process of protein synthesis. The possibility that genistein acts on the transcription process in osteoblastic MC3T3-E1 cells cannot be excluded.

Estrogenic compound $17 \beta$-estradiol and genistein mediate very different actions on osteoblastic cells [58], although genistein can bind to estrogen receptor- $\beta$. While $17 \beta$-estradiol may stimulate bone anabolism, in part, by antagonizing TNF- $\alpha$-induced NF- $\kappa B$ activation, genistein does not only fails to prevent the cytokin-induced NF- $\kappa B$ activation, but directly promotes NF- $\kappa B$ activation in MC3T3 cells [58]. These observations suggest mechanistic differences in the mechanisms by which $17 \beta$-estradiol and genistein promote osteoblast differentiation [58].

Genistein suppresses osteoclastic bone resorption: $\mathrm{PTH}, \mathrm{PGE}_{2}$, and LPS have stimulatory effects on bone resorption in in vitro culture system. Culture with PTH, PGE 2 or LPS clearly stimulated bone resorption in the femoral-metaphyseal tissues cultured for 48 hours, when bone resorption was estimated with a decrease in calcium content and production of lactic acid in the bone tissues [59]. The effects of bone-resorbing factors were completely suppressed in the presence of genistein [59]. Thus, genistein has been found to have suppressive effects on bone resorption.

Culture with $\mathrm{PTH}, \mathrm{PGE}_{2}, 1,25(\mathrm{OH})_{2} \mathrm{D}_{3}$ or LPS induced a remarkable increase in the formation of osteoclast-like multinucleated cells from mouse bone marrow cells [60]. These increases were suppressed in the presence of genistein [60]. Suppressive effects of genistein $\left(10^{-5} \mathrm{M}\right)$ were equal to effects of other anti-bone-resorbing agents (calcitonin, $17 \beta$-estradiol, and zinc sulfate) on osteoclast-like cell formation in mouse marrow culture [60]. Suppressive effects of genistein on osteoclast-like MNC formation in mouse marrow culture were greater than that of daidzein [60]. The cellular mechanism by which genistein suppresses osteoclast-like cell formation from marrow cells has been shown to be involved in cyclic AMP signaling [60].

Genistein has been found to induce cell death (apoptosis) of osteoclasts isolated from rat femoral tissues [61]. Suppressive effects of genistein on mature osteoclasts are partly mediated through the pathway of $\mathrm{Ca}^{2+}$ signaling [61]. Genistein may stimulate $\mathrm{Ca}^{2+}$ entry into osteoclasts. Daidzein has also been shown to suppress the number of mature osteoclasts, although daidzein did not have greater suppressive effects than genistein [61].

Culture with genistein has been found to have an inhibitory effect on protein tyrosine kinase activity in mature osteoclasts [62]. Genistein may partly induce apoptosis of osteoclasts through a mechanism that inhibits protein tyrosine kinases in the cells, since tyrosine kinase Src is implicated in the process of osteoclast-induced bone resorption in vitro and in vivo [63].

Culture with genistein has also been found to cause a significant increase in protein tyrosine phosphatase activity in mature osteoclasts [62]. This effect was also seen after the addition of genistein to the enzyme reaction mixture in vitro. Genistein can directly activate protein tyrosine phosphatase in mature osteoclasts. Protein tyrosine phosphatase (Src homology 2 domain-containing tyrosine phosphatase) is a negative regulator of osteoclastogenesis and osteoclast-resorbing activity in mutant mice [63]. Suppressive effects of genistein on mature osteoclasts may partly be mediated through the activation of protein tyrosine phosphatase in the cells. Genistein did not have an effect on $\beta$-glucuronidase activity in osteoclasts [62]. The effects of genistein in inhibition of osteoclastic bone resorption may not be implicated in the activity of lysosomal enzymes in the cells. As described above, suppressive effects of genistein on mature osteoclasts may be involved in the induction of apoptosis mediated through $\mathrm{Ca}^{2+}$ siganaling mechanism, inhibition of protein kinase, and activation of protein tyrosine phosphatase in the cells.

\section{Combination with zinc and genistein has potential synergistic effects on osteogenesis}

Synergistic effects of zinc and genistein in osteoblastic bone formation: The effect of zinc sulfate ( $5.5 \mathrm{mg} / \mathrm{kg}$ body weight) on increasing DNA and calcium contents in the femoral tissues has been found to synergisctically enhance after simultaneous administration of genistein $(100 \mu \mathrm{g} / \mathrm{kg}$ body weight) in vivo [64-66]. Oral administration of genistein $(100$ and $300 \mu \mathrm{g} / \mathrm{kg}$ ) or zinc sulfate (1 and $5 \mathrm{mg} \mathrm{Zn/}$ $\mathrm{kg}$ ) to female rats for 3 days caused a significant increase in alkaline phosphatase activity, DNA, and calcium content in the femoralmetaphyseal tissues in vivo. Combination of zinc and genistein may be a useful tool in the prevention and therapy of osteoporosis.

The cellular and molecular mechanisms by which zinc enhances anabolic effect of genistein on bone components have been examined. Combination of zinc $\left(10^{-5}\right.$ or $\left.10^{-4} \mathrm{M}\right)$ and genistein $\left(10^{-6}\right.$ or $\left.10^{-5} \mathrm{M}\right)$ was found to have synergistic effects on protein content in osteoblastic MC3T3-E1 cells in vitro [67]. This effect may involve in the activation of aminoacyl-tRNA synthase by zinc and genistein, since these factors can increase the enzyme activity in the cytosol of osteoblastic cells in vitro [67].

Alkaline phosphatase is an enzyme marker of osteoblasts, and the enzyme participates in bone mineralization [68]. $\alpha 1$ (I) collagen is a matrix protein that is related to bone formation and mineralization in osteoblast lineage cells [69]. Osteocalcin is a bone matrix protein containing $\gamma_{2}$-carboxyglutamin acid, which is synthesized in osteoblasts and is the protein involved in mineralization [69]. The expressions of alkaline phosphatase, a1 (I) collagen, and osteocalcin mRNAs in osteoblastic cells were synergistically enhanced after culture with the 
combination of zinc $\left(10^{-5}\right.$ or $\left.10^{-4} \mathrm{M}\right)$ and genistein $\left(10^{-6}\right.$ or $\left.10^{-5} \mathrm{M}\right)$ as compared to the effect of each factor [67]. This finding demonstrates that the combination of zinc and genistein has synergistic effects on gene expression in osteoblastic cells.

The effect of combination of zinc $\left(10^{-4} \mathrm{M}\right)$ and genistein $\left(10^{-5} \mathrm{M}\right)$ on the gene expression in osteoblastic cells was completely prevented in the presence of an inhibitor of protein synthesis or an inhibitor of transcriptional activity [67]. This suggests that the combination of genistein and zinc stimulates the transcriptional process in osteoblastic cells. Zinc or genistein has stimulatory effects on protein synthesis at the transcriptional process. Presumably, combination of zinc and genistein stimulates both transcriptional and translational activities in osteoblastic cells. Each factor activates aminoacyl-tRNA synthetase at the transcriptional process in osteoblastic cells. Zinc or genistein may have an effect on the binding of transcriptional factor(s), which is synthesized through translational process, to the nuclear DNA in osteoblastic cells.

Culture with zinc $\left(10^{-4} \mathrm{M}\right)$ or genistein $\left(10^{-5} \mathrm{M}\right)$ has stimulatory effects on the mineralization in osteoblastic cells [67]. Combination of zinc and genistein synergistically enhanced mineralization in osteoblastic cells. This finding was supported the view that the combination of zinc and genistein can effectively enhance bone mineralization, thereby increasing bone mass [67]

Synergistic effects of zinc and genistein in osteoclastic bone resorption: Moreover, combination of zinc $\left(10^{-5} \mathrm{M}\right)$ and genistein $\left(10^{-6} \mathrm{M}\right)$ has been shown to have potential suppressive effects on osteoclastic cells, which are generated in mouse marrow culture in the presence of M-CSF and RANKL in vitro [70]. The number of mature osteoclastic cells was synergistically decreased with culture of zinc $\left(10^{-5}\right.$ M) plus genistein $\left(10^{-6} \mathrm{M}\right)$ as compared with the value of each factor. Combination of zinc and genistein had potential suppressive effects on mature osteoclastic cells [70]. This effect was remarkable in the presence of M-CSF and RANKL, which are cytokines that stimulate osteoclastogenesis [70]. Culture with zinc or genistein caused a synergistical increase in DNA fragmentation in osteoclastic cells [70], indicating that both factors stimulate apoptotic cell death. In addition, zinc plus genistein-induced cell death was significantly prevented in the presence of caspase-3 inhibitor [70]. The stimulation of apoptotic cell death with the combination of zinc and genistein may be partly mediated through activation of caspase-3.

Zinc $\left(10^{-5} \mathrm{M}\right)$ increases the expression of caspase- 3 mRNA in osteoclastic cells cultured with or without M-CSF and RANKL, while genistein $\left(10^{-6} \mathrm{M}\right)$ alone did not have an effect [70]. The effect of zinc was significantly enhanced with the combination of genistein. Such effect was completely inhibited after culture with an inhibitor of protein synthesis or an inhibitor of transcriptional activity in osteoclastic cells [70], suggesting that the effect with the combination of zinc and genistein is involved in protein synthesis and transcription activation in osteoclastic cells.

Activation of tartrate-resistant acid phosphatase (TRACP) or cathepsin $\mathrm{K}$ plays a role in the promotion of osteoclastic bone resorption by stimulating the decomposition of bone matrix [36,37]. The expression of TRACP and cathepsin K mRNAs was markedly decreased in the presence of genistein plus zinc in osteoclastic cells cultured with M-CSF and RANKL [70]. Combination of zinc and genistein has potential suppressive effects on bone-resorbing activity.

Thus, combination of zinc and genistein has been found to have additive or synergistic effects in the suppression of osteoclastogenesis, mature osteoclast cell death, and bone resorption-related gene expression in osteoclastic cells.

Supplemental intake of zinc and genistein has potential effects against bone loss: As mentioned above, combination of zinc and genistein has been demonstrated to have potential synergistic effects on both stimulation of osteoblastic bone formation and suppression of osteoclastic bone resorption. Combination of zinc and genistein may have potential effects in the prevention and treatment of bone loss with various pathophysiologic states.

Zinc and genistein largely contain in fermented soybeans (natto). The effects of experimental diets with fermented soybeans containing zinc and genistein on OVX-induced bone loss has been demonstrated [71]. Experimental diets containing 2.1 to $9.7 \mathrm{mg}$ of zinc per $100 \mathrm{~g}$ of diet and 44.6 to $92.4 \mathrm{mg}$ of isoflavones (including genistein, genistein, daidzein, and daidzein) per $100 \mathrm{~g}$ of diet was fed to OVX rats for 3 months. OVX caused a significant reduction in the dry weight, mineral density, calcium content, zinc content, and alkaline phosphatase activity in the femoral tissues [71]. These reductions were prevented with feeding a natto diet. Such effect was significantly enhanced in OVX rats fed a natto diet supplemented with zinc and isoflavone of more amounts. Prolonged intake of dietary natto supplemented with zinc and isoflavone has a preventive effect on OVX-induced bone loss, suggesting that it may have a role in the prevention and treatment of osteoporosis.

Change in circulating biochemical markers of bone metabolism in aged individuals with the intake of fermented soybean (natto), which was made from isoflavone-rich soybean, supplemented with zinc has been examined [72]. Sixty-three volunteers (31 men and 32 women) were divided into four groups of 15 or 16 male volunteers and 16 or 16 female volunteers, and each group was sequentially given natto (40 g pack) containing two different levels of zinc once a day for 4 or 8 weeks as follows: either regular natto with naturally occuring isoflavone $35.0 \mathrm{mg}$, zinc $0.8 \mathrm{mg}$ and calcium $51.4 \mathrm{mg}$ or supplemented natto containing isoflavone $35.0 \mathrm{mg}$, zinc $3.6 \mathrm{mg}$, and calcium 60.0 mg. As serum bone markers, bone-specific alkaline phosphatase, $\gamma$-carboxylated osteocalcin, bone tartrate-resistant acid phosphatase (TRACP), and $\mathrm{N}$-telopeptide of type I collagen were assayed. The intake of regular natto for 4 or 8 weeks in men or women persons caused a significant increase in $\gamma$-carboxylated osteocalcin, a marker of bone formation, and a significant decrease in serum bone $\mathrm{N}$-teleopeptide of type I collagen, a marker of bone resorption, as compared with the value before intake [72]. Moreover, the intake of zinc-supplemented natto for 8 weeks in men or women caused a significant increase in serum bone-specific alkaline phosphatase activity and $\gamma$-carboxylated osteocalcin concentration and a significant decrease in serum bone TRACP activity and N-telopeptide of type I collagen, as compared with the values with the intake of regular natto [72].

This study have demonstrated that the intake of regular natto with genistein-rich soybean has stimulatory effects on bone formation and suppressive effects on bone resorption in aged individuals, and that such effect is synergistically enhanced with supplementation of zinc.

As described above, combination of zinc and genistein has been shown to have synergistic effects on the stimulation of osteoblastic bone formation and the suppression of osteoclastic bone resorption. Supplementation with composition of zinc compound and pure genistein may be potential tool in the prevention and therapy of osteoporosis with various pathophysiolocal conditions. 


\section{Synergistic effects of zinc and menaquinone-7 on osteogenesis}

Role of vitamin $\mathrm{K}$ in bone metabolism: Vitamin $\mathrm{K}$ is a fatsoluble vitamin that was originally identified as an essential factor for blood coagulation. Vitamin $\mathrm{K}$ is an essential cofactor for the post-translational carboxylation of certain protein-bound glutamate residues of osteocalcin, a synthesized by osteobalsts, which are converted into gamma-carboxy glutamate (Gla) by $\gamma$-carboxylase [73]. These Gla residues form calcium-binding sites that are essential for the activity of the proteins.

There are three types of vitamin $\mathrm{K}$ : vitamin $\mathrm{K}_{1}$ (phylloquinone), vitamin $\mathrm{K}_{2}$ (menaquinone), and vitamin $\mathrm{K}_{3}$ (menadione). Vitamin $\mathrm{K}_{1}$ is a sole compound, but vitamin $\mathrm{K}_{2}$ is a series of vitamers with multiisoprene units (one to four) at the 3-position of the naphthoquinone. Vitamin $\mathrm{K}_{2}$ (menaquinone-4; MK-4) has four isoprene units. MK-4 is essential for the $\gamma$-carboxylation of osteocalcin [73]. MK-4 has been shown to inhibit bone loss, which may be related to its side chain, in ovariectomized rats [74]. Natural menaquinone-7 (MK-7; vitamin $\mathrm{K}_{2}$ ) with seven isoprene units is very abundant in the fermented soybean (natto). It has been shown that serum MK-7 concentration in women living in Tokyo, where the fermented soybean is consumed, is about ten times higher than that of those living in Europe [75]. These differences may result from the intake of fermented soybean.

There is growing evidence for the roles of vitamin $\mathrm{K}_{2}$ in bone health in human subjects $[76,77]$. Clinically, vitamin $\mathrm{K}_{2}$ maintains lumbar bone mineral density (BMD) and prevents osteoporotic fractures in patients with osteoporosis. Osteocalcin, which is newly synthesized by osteoblasts, is released into circulation. For this reason, the circulating levels of osteocalcin are considered sensitive markers of bone formation [78]. A poor vitamin $\mathrm{K}$ status will lead to production of undercarboxylated (inactive) osteocalcin (unOC) [79]. In postmenopausal women, a clear association between elevated unOC and increased fracture risk have been found [80]. Significantly lower levels of vitamin $K_{1}$ and vitamin $K_{2}$ have been found in the serum obtained from elderly patients within a few hours after a hip fracture [80]. A daily vitamin $K_{1}$ supplement of $80 \mu \mathrm{g}$ seems to be necessary to reach a premenopausal carboxylated osteocalcin/total osteocalcin ratio [81]. An adult daily intake of about $100 \mu \mathrm{g}$ of vitamin $\mathrm{K}_{1}$ is recommended for the maintenance of hemostasis [82].

Common risk factors for vitamin $\mathrm{K}$ deficiency in the hospitalized patient include inadequate dietary intakes, malabsorption syndromes (especially owing to chlestatic liver disease), antibiotic therapy, and renal insufficiency [83]. Pregnant women and their newborns present a special risk category because of poor placental transport and low concentrations of vitamin K in breast milk [83]. Since 2000, the Food and Drug Administration (FDA) has mandated that adult parenteral preparations should provide a supplemental amount of $150 \mu \mathrm{g}$ vitamin $\mathrm{K}_{1}$ per day in addition to that present naturally [83]. Although this supplemental daily amount is probably beneficial in preventing vitamin $\mathrm{K}$ deficiency, it may be excessive for patients taking vitamin $\mathrm{K}$ antagonists, such as warfarin, and jeopardize their anticoagulation control. Natural forms of vitamin K have no proven toxicity.

MK-7 stimulates osteoblastic bone formation: MK-7, which was isolated from fermented soybean (natto), has been found to have a stimulatory effect on calcification in the femoral tissues obtained from normal young rats in vitro [84]. The action of MK-7 on bone calcification has been shown to have the same effect as MK-4. MK-7 has partially been converted to MK-4 in the body. MK-7 may have an important role in the regulation of bone metabolism. Culture with MK-7 $\left(10^{-6}\right.$ or $\left.10^{-5} \mathrm{M}\right)$ caused a significant increase in biochemical components (alkaline phosphatase acitivy, DNA and calcium contents) in the femoral-diaphyseal (cortical bone) and -metaphyseal (trabecular bone) tissues obtained from aged rats in vitro [85]. The effect of MK-7 was significantly enhanced in the presence of genistein $\left(10^{-6}\right.$ or $10^{-5}$ $\mathrm{M})$, suggesting that the mode of action of MK-7 differs from that of genistein [85]. The effect of MK-7 in increasing bone components in the femoral tissues was completely depressed in the presence of cycloheximide, an inhibitory of protein syntheasis in vitro [85]. Thus, MK-7 has a stimulatory effect on bone formation in vitro.

Culture with MK-7 $\left(10^{-6}\right.$ or $\left.10^{-5} \mathrm{M}\right)$ caused a significant increase in alkaline phosphatase activity, protein and DNA contents in osteoblastic cells [86]. Such effects of MK-7 were completely depressed in the presence of cycloheximide. MK-7 has a stimulatory effect on osteoblastic bone formation due to increasing protein synthesis including osteocalcin.

MK-7 suppresses osteocalstic bone resorption: MK-7 has been shown to have suppressive effects on oteoclastic bone resoption in vitro [87]. Culture with bone-resorbing factors, PTH and PGE, caused a significant decrease in calcium content and lactic acid production in the femoral-metaphyseal tissues obtained from young and aged rats in vitro [87]. Such effects of bone-resorbing factors were completely suppressed after culture with MK-7 $\left(10^{-7}-10^{-5} \mathrm{M}\right)$, indicating that MK-7 has an inhibitory effect on bone resorption in bone tissue culture [87].

Osteoclast-like cells are formed from bone marrow cells in the presence of bone-resorbing factors (PTH or $\mathrm{PGE}_{2}$ ) [87]. PTH- or $\mathrm{PGE}_{2}-$ induced increase in osteoclast-like cell formation was significantly suppressed after culture with MK-7 [87]. MK-7 had potential inhibitory effects at the later stage of differentiation of marrow cells. Osteoclast-like cell formation was stimulated when dibutyryl cyclic AMP (DcAMP) or PMA, an activator of protein kinase $C$, was added to the culture medium. MK-7 significantly suppressed the effect of PMA on osteoclast-like cell formation, although it did not have an inhibitory effect on DcAMP-induced increase in osteoclast-like cell formation [87]. These observations suggest that the suppressive effect of MK-7 is partly involved in protein kinase C signaling [87].

The effect of MK-7 on mature osteoclasts isolated from rat femoral tissues has been examined [87]. Culture with MK-7 caused a significant decrease in the number of mature osteoclasts. Such a decrease was also seen in the presence of calcitonin, DcAMP, or calcium chloride [87]. The effect of MK-7 in decreasing the number of osteoclasts was completely abolished in the presence of dibucaine or staurosporine, which are inhibitors of $\mathrm{Ca}^{2+}$-dependent protein kinases. Suppressive effects of MK-7 on osteoclasts may be partly mediated through the pathway of $\mathrm{Ca}^{2+}$ - and cyclic AMP-dependent signalings [87].

Mechanism of MK-7 action: MK-7 has been shown to stimulate osteoblastic bone formation and osteoclastic bone resorption, thereby increasing bone mass. MK-7 may activate $\gamma$-carboxylase that glutamate residues of osteocalcin are converted into $\gamma$-carboxyglutamate in osteoblastic cells. MK-7 stimulates protein synthesis including osteocalcin in osteoblastic cells [86]. This action may be important as a mechanism by which MK-7 regulates bone homeostasis.

Activation of NF- $\mathrm{kB}$ signal transduction pathway is essential for osteoclast formation and resorption. By contrast, NF- $\mathrm{kB}$ signaling potently antagonizes osteoblast differentiation and function. MK-7 action on osteoblast and osteoclast formation and activity is 
accomplished by downregulating basal and cytokine-induced NF- $\kappa \mathrm{B}$ activation, by increasing I $\mathrm{B}$ mRNA, in a $\gamma$-carboxylation-independent manner [88]. MK-7 prevented repression by TNF- $\alpha$ of Smad signaling induced by either TGF- $\beta$ or BMP-2 [87]. MK-7 further antagonized receptor activator of NF- $\kappa B$ (RANK) ligand (RANKL)-induced NF$\kappa \mathrm{B}$ activation in osteoclast precursors [87]. These findings provide a novel mechanism to explain the dual pro-anabolic and anti-catabolic activities of vitamin $\mathrm{K}_{2}$, Moreover, the suppressive effect of MK-7 on mature osteoclasts may be partly mediated through the pathway of $\mathrm{Ca}^{2+}$ - and cyclic AMP-dependent signaling [87].

Vitamin $\mathrm{K}_{2}$ has also been shown to be a transcriptional regulator of bone-specific genes that actthrough steroid and xenobiotic receptors (SXRs) to promote expression of osteoblastic markers [89].

Intake of MK-7 prevents bone loss in animal model for osteoporosis: MK-7 has been shown to have preventive effects on osteoporosis. The preventive effect of dietary MK-7 on bone loss in ovariectomized (OVX) rats has been examined [90]. OVX rats were given experimental diets containing MK-4 (12 mg/100 g diet) or MK-7 ( $18.1 \mathrm{mg} / 100 \mathrm{~g}$ diet) for 24 days; MK-4 and MK-7 were equal in molar concentration [90]. This feeding caused a remarkable increase in MK-4 and MK-7 concentrations in the serum and femur of OVX rats. OVX-induced decrease in the femoral dry weight and femoral calcium content were prevented after feeding with dietary MK-4 or MK-7 [90].

In separate experiments, OVX rats were given experimental diets containing fermented soybeans (natto including MK-7, 9.4 $\mu \mathrm{g} / 100 \mathrm{~g}$ diet) with or without added MK-7 (37.6 $\mu \mathrm{g} / 100 \mathrm{~g}$ diet) for 77 days [90]. Feeding produced a significant elevation of MK-4 and MK-7 concentrations in the serum of OVX rats. The decreases in the femoral dry weight and femoral calcium content induced by OVX were significantly prevented after feeding with diets containing natto with MK-7 added (37.6 $\mu \mathrm{g} / 100 \mathrm{~g}$ diet) [90]. Supplementation of MK-7 was found to have a preventive effect on OVX-induced bone loss. This effect may be partly contributed to MK- 4 that is formed after degradation of MK-7 in body.

Moreover, the effect of prolonged intake of dietary MK-7 on bone loss in OVX rats has been shown [91]. OVX rats were given experimental diets containing natto (including MK-7, $9.4 \mu \mathrm{g} / 100 \mathrm{~g}$ diet) with or without supplemental MK-7 (containing 14.1 or $18.8 \mu \mathrm{g} / 100 \mathrm{~g}$ diet) for 150 days [91]. Feeding produced a significant elevation of the serum MK-7 concentration of OVX rats [91]. Serum $\gamma$-carboxylated osteocalcin concentration was significantly decreased after OVX. This decrease was significantly prevented after supplementation of MK-7 (18.8 $\mu \mathrm{g} / 100 \mathrm{~g}$ diet) [91]. OVX caused a significant decrease in femoral dry weight, femoral calcium content, and mineral density. These decreases were significantly prevented after supplementation of MK-7 (total, $18.8 \mu \mathrm{g} / 100 \mathrm{~g}$ diet) [91]. Co-relationship with dietary MK-7 intake and bone formation markers in OVX rats showed a good corelationship [91].

Thus, prolonged intake of MK-7 has been shown to have a preventive effect on bone loss induced by OVX. MK-7 may be useful in the prevention and treatment of osteoporosis.

Dietary MK-7 intake increases osteocalcin production in human subjects: The change in circulating MK-7 and $\gamma$-carboxylated osteocalcin (Gla osteocalcin) concentrations in normal individuals with the intake of fermented soybean has been examined [92,93]. Fortyeight volunteers ( 45 men and 3 women) were divided into three groups of 16 volunteers each (15 men and 1 women), and each group was given sequentially natto $(50 \mathrm{~g})$ containing three different amounts of MK-7 once a day for 14 days as follows: either regular natto with MK-7 865 $\mu \mathrm{g} / 100 \mathrm{~g}$ diet of natto, reinforced natto containing MK-7 $1295 \mu \mathrm{g} / 100$ $\mathrm{g}$, or MK-7 $1730 \mu \mathrm{g} / 100 \mathrm{~g}$ [92]. Serum MK-7 was not found in normal individuals who had not eaten natto. Serum MK-7 and $\gamma$-carboxylated osteocalcin concentrations were significantly raised 7, 10, and 14 days after the start of the intake of reinforced natto containing MK-7 1295 or $1730 \mu \mathrm{g} / 100 \mathrm{~g}$ [93]. Serum $\gamma$-carboxylated osteocalcin concentration was significantly elevated at 14 days after the intake of natto containing either 1295 or $1730 \mu \mathrm{g}$ of MK-7/100 g diets as compared with that after regular natto intake [93]. The intake of reinforced natto that contains more MK-7 than regular natto may play a role in the prevention of age-related bone loss.

The effect of low-dose MK-7 supplementation on bone health has been examined [94]. Healthy postmenopausal women $(n=244)$ received for 3 years placebo or MK-7 (180 $\mu$ g MK-7/day) capsules [94]. Bone mineral density (BMD) of lumbar spine, total hip, and femoral neck was measured by DXA; bone strength indices of the femoral neck were calculated. Vertebral fracture assessment was performed by DXA and used as measure for vertebral fractures. Circulating uncarboxylated osteocalcin (ucOC) and carboxylated OC (cOC) were measured; the $\mathrm{ucOC} / \mathrm{cOC}$ ratio served as marker of vitamin $\mathrm{K}$ status [94]. Measurements occurred at baseline and after 1, 2, and 3 years of treatment. MK-7 intake significantly improved vitamin $\mathrm{K}$ status and decreased the age-related decline in bone mineral content and BMD at the lumbar spine and femoral neck, but not at the total hip [94]. Bone strength was also favorably affected by MK-7. MK-7 significantly decreased the loss in vertebral height of the lower thoracic region at the mid-site of the vertebrae [94]. MK-7 supplements may help postmenopausal women to prevent bone loss.

Synergistic effects of zinc and MK-7 in osteoporosis treatment: Zinc has been shown to synergistically enhance the effect of MK-7 in increasing bone calcium content in vitro [84] and in vivo [95]. Rats were orally administered either vehicle (distilled water), zinc sulfate $(10 \mathrm{mg}$ $\mathrm{Zn} / \mathrm{kg}$ body weight), MK-7 (5 mg/kg), or zinc (10 mg/kg) plus MK-7 (5 $\mathrm{mg} / \mathrm{kg}$ ) once a day for 7 days [95]. Femoral dry weight was significantly increased after the administration of both zinc and MK-7, although a significant change was not seen after the administration of zinc or MK-7 alone [95]. Calcium content in the femoral-diaphyseal and metaphyseal tissues was significantly increased after zinc administration [95]. Such an increase was not found after MK-7 alone. Bone calcium content was synergistically enhanced after the administration of both zinc and MK-7 [95]. Alkaline phosphatase activity and DNA content in the diaphyseal and metaphyseal tissues were significantly increased by administration of zinc or MK-7 alone; these increases were additively enhanced by both zinc and MK-7 [95]. Moreover, supplemental intake containing both zinc $(16.75 \mathrm{mg} / \mathrm{kg})$ and MK-7 $(16.88 \mu \mathrm{g} / \mathrm{kg})$ once a day for 15 days caused synergistic increase in femoral dry weight, alkaline phosphatase activity, DNA, calcium and zinc contents in the diaphyseal and metaphyseal tissues of female elderly rats [95]. Thus, supplemental intake with the combination of MK-7 and zinc may be useful in the prevention and treatment of osteoporosis.

\section{Synergistic effects of zinc and vitamin $\mathrm{D}_{3}$ on osteogenesis}

Role of vitamin $\mathrm{D}_{3}$ in bone metabolism: Calcium, phosphorus and vitamin $\mathrm{D}$, which are nutrients, were noticed in maintaining bone health with preservation of bone mineral components. Calcium and phosphorus are essential elements in bone composition and are regulated through calcium-regulating hormones including PTH, 
1, 25-dihydroxyvitamin $\mathrm{D}_{3}\left[1,25(\mathrm{OH})_{2} \mathrm{D}_{3}\right]$ and calcitonin. Nutrient vitamin $\mathrm{D}$ is converted to hydroxyvitamin $\mathrm{D}_{3}\left[25(\mathrm{OH}) \mathrm{D}_{3}\right]$ in the liver and then $1,25(\mathrm{OH})_{2} \mathrm{D}_{3}$ in the kidney which are its active metabolite. These forms are hormone recognized to play a critical function in bone metabolism. This is evidenced by formation of poorly mineralized bone during vitamin $\mathrm{D}$ deficiency leading to rickets in children and osteomalacia in adults.

This is largely a consequence of the necessity for vitamin $\mathrm{D}_{3}$ to promote efficient calcium absorption in the small intestine. Any decline in serum calcium concentrations due to inadequate calcium absorption leads to a secondary hyperparathyroidism that catabolizes the skeleton to maintain a physiological level of calcium necessary for normal cellular metabolism [96].

Although vitamin D supplementation is commonly used to combat osteoporosis, currently the optimal dose of vitamin $\mathrm{D}$ required for fracture prevention is contentious. While a minimum of $10 \mathrm{ng} / \mathrm{mL}$ of $25(\mathrm{OH}) \mathrm{D}_{3}$ is sufficient to prevent rickets and osteomalacia [97], recent studies have demonstrated that a minimum threshold $25(\mathrm{OH}) \mathrm{D}_{3}$ level of $29.7 \mathrm{ng} / \mathrm{mL}$ is necessary for protection from fracture [98]. However, there is a paucity of data as to the optimal vitamin $\mathrm{D}_{3}$ concentration for fracture prevention and to complicate matters it is now appreciated that vitamin $\mathrm{D}_{3}$ plays a number of extra-skeletal roles including promotion of innate and adaptive immune function, prevention of cancers, and prevention of hypertension $[97,98]$. The doses of vitamin $D$ is needed to achieve these extra-skeletal actions may be considerable higher than that needed to effect its actions on the skeleton [99]. Recent meta-analysis has suggested that supplementation of greater than $400 \mathrm{IU}$ of vitamin $\mathrm{D}$ may reduce fractures [100], however the mechanism is unclear and may be associated in part with decreased risk of falling as a consequence of improved neuromuscular function [101]. In a clinical study of bedridden older patients with chronic secondary hyperparathyroidism, low dose (400 IU/d) vitamin D supplementation led to a significant increase in amino-terminal propeptide of type I procollagen, a marker of in vivo bone formation. These gains were complete negated by high dose $(1200 \mathrm{IU} / \mathrm{d})$ vitamin D supplementation, while indices of bone resorption did not significantly change with either regimen [102]. In another study, wintertime vitamin D supplementation of healthy men led to a significant dose-dependent decline in bone specific alkaline phosphatase, a marker of in vivo mineralization [103].

As the vast majority of studies involve vitamin D supplementation in the context of antiresorptive therapy, typically a bisphosphonate, it becomes extremely difficult to assess and effects of vitamin D alone on bone turnover given that antiresorptive agents themselves potently suppress bone formation as a consequence of coupling. Furthermore, the amelioration of secondary hyperparathyroidism by vitamin $\mathrm{D}$ supplementation is often associated with a decline in bone turnover [104]. This may be a consequence of reduced parathyroid hormone (PTH)-driven bone resorption leading to reduced bone formation as a consequence of coupling.

Vitamin D further appears to have hallmarks of an antiinflammatory agent as vitamin $\mathrm{D}$ deficiency has been linked to a number of different inflammatory conditions including inflammatory bowel disease and rheumatoid arthritis, which induce bone loss. In a population-based prospective cohort, vitamin D intake was inversely correlated with risk of rheumatoid arthritis [96], an inflammatory autoimmune disease. Furthermore, vitamin D insufficiency promotes the development of autoimmunity in animal models of inflammatory bowel disease [96].
Zinc synergistically enhances osteogenic effects of vitamin $\mathbf{D}_{3}$ : The synergistic effects with the combination of vitamin $\mathrm{D}_{3}$ and zinc on osteogenesis have been found in the femur of weanling rats [105] and aged rats [106]. Oral administration of vitamin $\mathrm{D}_{3}(10 \mu \mathrm{g} /$ $\mathrm{kg}$ body weight) did not cause any increase in zinc accumulation in the femoral tissue following treatment with zinc sulphate $(10 \mathrm{mg} \mathrm{Zn/}$ $\mathrm{kg}$ ) [105]. Administration of vitamin $\mathrm{D}_{3}$ or zinc caused significant increases in alkaline phosphatase activity and DNA content of the femoral diaphysis [105]. The increase in bone alkaline phosphatase activity was additionally enhanced by simultaneous administration of vitamin $\mathrm{D}_{3}$ and zinc [105]. Moreover, bone DNA content was synergistically enhanced (about 4 times) after the administration with combination of vitamin $\mathrm{D}_{3}$ and zinc [105]. The synergistic effect was also seen with combination of vitamin $\mathrm{D}_{3}(5 \mu \mathrm{g} / \mathrm{kg})$ and zinc $(10 \mathrm{mg} /$ $\mathrm{kg}$ ) [105]. Such synergistic effects on bone alkaline phosphatase activity were suppressed after treatment with cycloheximide or actinomycin D [105]. Moreover, aging has been shown to cause decreases in calcium content, alkaline phosphatase activity and DNA content in the femoral tissues of rats [106]. Such decreases were found to restore after the administration of vitamin $\mathrm{D}_{3}$, and this steroid effect was synergistically enhanced with the combination of zinc [106].

Whether the synergistic effects with the combination of zinc and vitamin $\mathrm{D}_{3}$ on osteogenesis are specific for this steroid has been examined using other calcium-regulating hormones [107]. Administration of $1,25(\mathrm{OH})_{2} \mathrm{D}_{3}(1.50 \mu \mathrm{g} / \mathrm{kg} \mathrm{BW})$ or PTH (1-34) $(100 \mathrm{U} / \mathrm{kg})$ produced significant increases in alkaline phosphatase activity and DNA content in the femoral diaphysis of rats in vivo, while calcitonin $(10 \mathrm{U} / \mathrm{kg})$ did not have a significant effect [107]. Among these hormones, both $1,25(\mathrm{OH})_{2} \mathrm{D}_{3}$ and zinc caused synergistic increases in bone alkaline phosphatase activity and DNA content [107]. Thus, synergistic effect with combination of zinc and $1,25(\mathrm{OH})_{2} \mathrm{D}_{3}$ on osteogenesis was unique among calcium-regulating hormones.

Synergistic effects with $1,25(\mathrm{OH})_{2} \mathrm{D}_{3}$ and zinc on osteogenesis has also shown in bone tissue culture in vitro [108]. Calvaria were

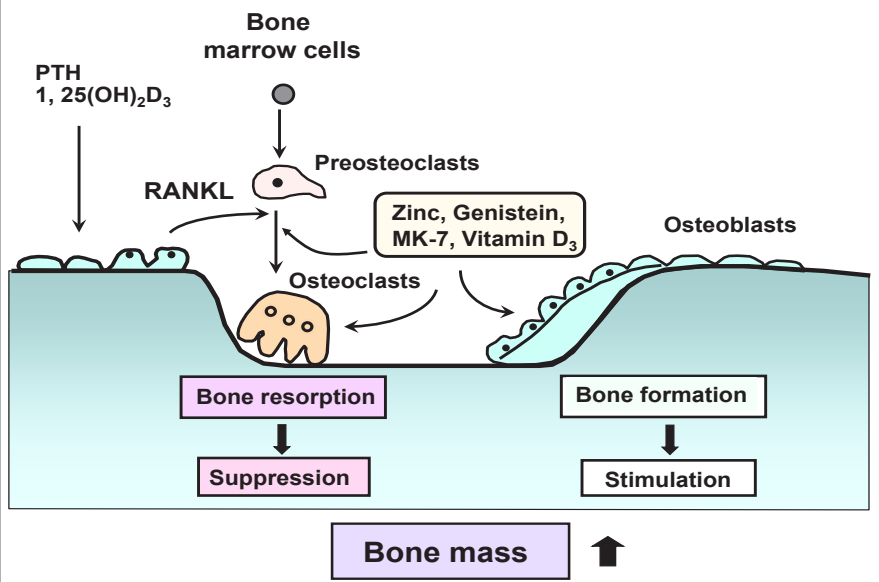

Figure 1: Functional food factors including zinc, genistein, menquinone-7 (MK-7), and vitamin $D_{3}$ stimulates osteoblastic bone formation and suppresses osteoclastic bone resporption, thereby increasing bone mass. These factors stimulate cell differentiation, cell proliferation, and mineralization in osteoblasts and suppress osteoclastogenesis that is induced by various bone-resorbing factors in bone marrow culture. These factors regulate protein synthesis and gene expression of various proteins, which are related to finctions of osteoblasts and osteoclatst. Zinc synergistically enhances stimulatory effects of genistein, MK-7 and vitamin $D_{3}$ on osteogenesis. 
removed from weanling rats. Bone calcium content and alkaline phosphatase activity were significantly increased after culture with $1,25(\mathrm{OH})_{2} \mathrm{D}_{3}\left(10^{-9}-10^{-7} \mathrm{M}\right)$, while bone acid phosphatase activity was not significantly changed [108]. $\left[{ }^{3} \mathrm{H}\right]$-Leucine incorporation by the bone tissues and bone DNA content were significantly increased after culture with $1,25(\mathrm{OH})_{2} \mathrm{D}_{3}\left(10^{-8}\right.$ and $\left.10^{-7} \mathrm{M}\right)$. Such effects of 1 , $25(\mathrm{OH})_{2} \mathrm{D}_{3}\left(10^{-7} \mathrm{M}\right)$ were synergistically enhanced in the presence of zinc $\left(10^{-4} \mathrm{M}\right)$ [108]. Thus, the stimulatory effects of $1,25(\mathrm{OH})_{2} \mathrm{D}_{3}$ on osteogenesis were found to synergistically enhance with the combination of zinc in bone tissue culture in vitro.

The receptors for $1,25(\mathrm{OH})_{2} \mathrm{D}_{3}$, an active hormonal type, have been shown to have two zinc fingers at the sit of interaction with DNA [109]. Possible mechanism by which zinc has a synergistic effect on vitamin $\mathrm{D}$-stimulated osteogenesis may be to enhance the interaction of $1,25(\mathrm{OH})_{2} \mathrm{D}_{3}$-receptor complexes with DNA at that site. In addition, zinc, which stimulates protein synthesis in osteoblastic cells, may increase receptor proteins for $1,25(\mathrm{OH})_{2} \mathrm{D}_{3}$ in the cells.

\section{Conclusion}

Osteoporosis is induced by alteration in balance of bone homeostasis with physiological aging, postmenopausal with ovarian hormone deficiency, inflammatory condition, obesity, diabetes and cancer bone metastasis. Bone loss with osteoporosis induces bone fracture. Functional food factors may help to prevent and treat bone loss and osteolysis. Among many functional food factors, essential trace element zinc, isoflavone genistein and vitamin $\mathrm{K}_{2}$ (menaquinon-7) has been shown to have stimulatory effects on osteoblastic bone formation and suppressive effects on osteoclastic bone resorption, thereby increasing bone mass.

Combination with zinc and other factors (including genistein, menaquinon-7, and vitamin $\mathrm{D}_{3}$ ) has been found to have synergistical osteogenic effects, as summarized in Figure 1. Supplemental intake with the combination of zinc and these factors may have potential effects in the prevention and treatment of bone loss with various pathophysiologic states.

Drugs, which are clinically used in the treatment of osteoporosis, are based on the action of osteoclastic bone resorption. Clinical compound that stimulates bone formation is very few. An intensive effort has begun to identify or develop anabolic agents capable of rebuilding lost bone mineral density. At present, teriparatide, a fragment of human parathyroid hormone, is the only the United State Food and Drug Administration (FDA) approved anabolic agent currently available. This agent represents a significant leap forward but as a biologic based agent its use is limited by high cost and the need for daily injection. Furthermore, therapy is not recommended for more than 2 years due to the potential for osteosarcoma. As a consequence there is intense interest in the identification of additional anabolic agents. Clinical compounds that stimulate bone formation are under development.

Supplementation with ingredients (including zinc, genistein, menaquinon-7 and vitamin $\mathrm{D}_{3}$ ), which has synergistical osteogenic effects, may be a potential tool in the therapy of osteoporosis. Development of new drug is expected using chemically pure ingredients as biomedical food factors.

\section{Author Contribution and Disclosures}

The author contributed to the design and conduct of the study, collection, analysis, and interpretation of data, and manuscript writing. Author has no conflicts of interest.

\section{Acknowledgements}

The author was partly supported by Awards of the Sato Memorial Fundation (Japan), the Mishima Kaiun Memorial Foundation (Japan), the Senji Miyata Foundation (Japan), and the Japan Society for Biomedical Research on Trace Elements

\section{References}

1. Riggs BL, Jowsey J, Kelly PJ, Jones JD, Maher FT (1969) Effect of sex hormones on bone in primary osteoporosis. J Clin Invest 48: 1065-1072.

2. Weitzmann MN, Pacifici R (2006) Estrogen deficiency and bone loss: an inflammatory tale. J Clin Invest 116: 1186-1194.

3. Bonjour J-P, Schurch M-A, Rizzori R (1996) Nutritional aspects of hip fracture Bone 18: 139S-144S.

4. Yamaguchi M (2010) Nutritional Factors and Osteoporosis Prevention. Nova Science Publishers, Inc., New York, USA.

5. Yamaguchi M (2010) Role of nutritional zinc in the prevention of osteoporosis Mol Cell Biochem 338: 241-254.

6. Raggatt LJ, Partridge NC (2010) Cellular and molecular mechanisms of bone remodeling. J Biol Chem 285: 25103-25108.

7. Chambers TJ, Fuller K (2011) How are osteoclasts induced to resorb bone? Ann N Y Acad Sci 1240: 1-6.

8. Canalis E, McCarthy T, Centrella M (1988) Growth factors and the regulation of bone remodeling. J Clin Invest 81: 277-281.

9. Inoue K, Matsuda K, Itoh M, Kawaguchi H, Tomoike H, et al. (2002) Osteopenia and male-specific sudden cardiac death in mice lacking a zinc transporter gene, Znt5. Hum Mol Genet 11: 1775-1784.

10. Khadeer MA, Sahu SN, Bai G, Abdulla S, Gupta A (2005) Expression of the zinc transporter ZIP1 in osteoclasts. Bone 37: 296-304.

11. Nakashima K, Zhou X, Kunkel G, Zhang Z, Deng JM, et al. (2002) The nove zinc finger-containing transcription factor osterix is required for osteoblast differentiation and bone formation. Cell 108: 17-29.

12. Komori T, Yagi H, Nomura S, Yamaguchi A, Sasaki K, et al. (1997) Targeted disruption of Cbfa1 results in a complete lack of bone formation owing to maturational arrest of osteoblasts. Cell 89: 755-764.

13. Shen ZJ, Nakamoto T, Tsuji K, Nifuji A, Miyazono K, et al. (2002) Negative regulation of bone morphogenetic protein/Smad signaling by Cas-interacting zinc finger protein in osteoblasts. J Biol Chem 277: 29840-29846.

14. Jones DC, Wein MN, Oukka M, Hofstaetter JG, Glimcher MJ, et al. (2006) Regulation of adult bone mass by the zinc finger adapter protein Schnurri-3. Science 312: 1223-1227

15. Shin JN, Kim I, Lee JS, Koh GY, Lee ZH, et al. (2002) A novel zinc finger protein that inhibits osteoclastogenesis and the function of tumor necrosis factor receptor-associated factor 6. J Biol Chem 277: 8346-8353.

16. Hsieh HS, Navia JM (1980) Zinc deficiency and bone formation in guinea pig alveolar implants. J Nutr 110: 1581-1588.

17. Oner G, Bhaumick B, Bala RM (1984) Effect of zinc deficiency on serum somatomedin levels and skeletal growth in young rats. Endocrinology 114 1860-1863.

18. Masters DG, Keen CL, Lönnerdal B, Hurley LS (1986) Release of zinc from maternal tissues during zinc deficiency or simultaneous zinc and calcium deficiency in the pregnant rat. J Nutr 116: 2148-2154.

19. Herzberg M, Foldes J, Steinberg R, Menczel J (1990) Zinc excretion in osteoporotic women. J Bone Miner Res 5: 251-257.

20. Yamaguchi M, Yamaguchi R (1986) Action of zinc on bone metabolism in rats. Increases in alkaline phosphatase activity and DNA content. Biochem Pharmacol 35: 773-777.

21. Yamaguchi M, Oishi H, Suketa $Y$ (1987) Stimulatory effect of zinc on bone formation in tissue culture. Biochem Pharmacol 36: 4007-4012.

22. Yamaguchi M, Oishi H, Suketa $Y$ (1988) Zinc stimulation of bone protein synthesis in tissue culture. Activation of aminoacyl-tRNA synthetase. Biochem Pharmacol 37: 4075-4080. 
23. Yamaguchi M, Matsui $R$ (1989) Effect of dipicolinate, a chelator of zinc, on bone protein synthesis in tissue culture. The essential role of zinc. Biochem Pharmacol 38: 4485-4489.

24. Hashizume M, Yamaguchi M (1993) Stimulatory effect of beta-alanyl-Lhistidinato zinc on cell proliferation is dependent on protein synthesis in osteoblastic MC3T3-E1 cells. Mol Cell Biochem 122: 59-64

25. Hashizume M, Yamaguchi M (1994) Effect of beta-alanyl-L-histidinato zinc on differentiation of osteoblastic MC3T3-E1 cells: increases in alkaline phosphatase activity and protein concentration. Mol Cell Biochem 131: 19-24.

26. Yamaguchi M, Kishi S, Hashizume M (1994) Effect of zinc-chelating dipeptides on osteoblastic MC3T3-E1 cells: activation of aminoacyl-tRNA synthetase. Peptides 15: 1367-1371.

27. Yamaguchi M, Hashizume M (1994) Effect of beta-alanyl-L-histidinato zinc on protein components in osteoblastic MC3T3-El cells: increase in osteocalcin, insulin-like growth factor-I and transforming growth factor-beta. Mol Cell Biochem 136: 163-169.

28. Matsui T, Yamaguchi M (1995) Zinc modulation of insulin-like growth factor's effect in osteoblastic MC3T3-E1 cells. Peptides 16: 1063-1068.

29. Yamaguchi M, Fukagawa M (2005) Role of zinc in regulation of protein tyrosine phosphatase activity in osteoblastic MC3T3-E1 cells: zinc modulation of insulinlike growth factor-l's effect. Calcif Tissue Int 76: 32-38.

30. Yamaguchi M, Matsui T (1996) Stimulatory effect of zinc-chelating dipeptide on deoxyribonucleic acid synthesis in osteoblastic MC3T3-E1 cells. Peptides 17: $1207-1211$

31. Yamaguchi M, Goto M, Uchiyama S, Nakagawa T (2008) Effect of zinc on gene expression in osteoblastic MC3T3-E1 cells: enhancement of Runx2, OPG, and regucalcin mRNA expressions. Mol Cell Biochem 312: 157-166.

32. Yamaguchi M, Segawa Y, Shimokawa N, Tsuzuike N, Tagashira E (1992) Inhibitory effect of beta-alanyl-L-histidinato zinc on bone resorption in tissue culture. Pharmacology 45: 292-300.

33. Kishi S, Yamaguchi M (1994) Inhibitory effect of zinc compounds on osteoclastlike cell formation in mouse marrow cultures. Biochem Pharmacol 48: 12251230.

34. Yamaguchi M, Kishi S (1996) Zinc compounds inhibit osteoclast-like cell formation at the earlier stage of rat marrow culture but not osteoclast function. Mol Cell Biochem 158: 171-177.

35. Yamaguchi M, Kishi S (1995) Inhibitory effect of zinc-chelating dipeptide on parathyroid hormone-stimulated osteoclast-like cell formation in mouse marrow cultures: involvement of calcium signaling. Peptides 16: 629-633.

36. Segawa Y, Tsuzuike N, Itokazu Y, Tagashira E, Yamaguchi M (1993) Effect of beta-alanyl-L-histidinato zinc on bone metabolism in rats with adjuvant arthritis. Biol Pharm Bull 16: 656-659.

37. Zaidi M, Blair HC, Moonga BS, Abe E, Huang CL (2003) Osteoclastogenesis, bone resorption, and osteoclast-based therapeutics. J Bone Miner Res 18: $599-609$

38. Asagiri M, Takayanagi $\mathrm{H}$ (2007) The molecular understanding of osteoclast differentiation. Bone 40: 251-264.

39. Yamaguchi M, Uchiyama S (2004) Receptor activator of NF-kappaB ligandstimulated osteoclastogenesis in mouse marrow culture is suppressed by zinc in vitro. Int J Mol Med 14: 81-85.

40. Eihorn TA (1998) The cell and molecular biology of fracture healing. Clin Orthop 355S: S7-S21.

41. Igarashi A, Yamaguchi M (1999) Increase in bone protein components with healing rat fractures: enhancement by zinc treatment. Int J Mol Med 4: 615-620.

42. Igarashi A, Yamaguchi M (2001) Increase in bone growth factors with healing rat fractures: the enhancing effect of zinc. Int J Mol Med 8: 433-438.

43. Igarashi A, Yamaguchi M (1999) Stimulatory effect of zinc acexamate administration on fracture healing of the femoral-diaphyseal tissues in rats. Gen Pharmacol 32: 463-469.

44. Yamaguchi M, Ozaki K (1990) Aging affects cellular zinc and protein synthesis in the femoral diaphysis of rats. Res Exp Med (Berl) 190: 295-300.

45. Yamaguchi M, Ehara $Y$ (1995) Zinc decrease and bone metabolism in the femoral-metaphyseal tissues of rats with skeletal unloading. Calcif Tissue Int 57: $218-223$

46. Yamaguchi M, Ehara $Y$ (1996) Effect of essential trace metal on bone metabolism in the femoral-metaphyseal tissues of rats with skeletal unloading: Comparison with zinc-chelating dipeptide. Calcif Tissue Int 59: 27-32.

47. Yamaguchi M, Kishi S (1994) Effect of zinc-chelating dipeptide on bone metabolism in weanling rats: comparison with beta-alanyl-L-histidinato zincrelated compounds. Peptides 15: 671-673.

48. Kisi S, Yamaguchi M (1994) Stimulatory effect of beta-alanyl-L-histidinato zinc on alkaline phosphatase activity in bone tissues from elderly rats: comparison with zinc sulfate action. Biol Pharm Bull 17: 345-347.

49. Kishi S, Segawa Y, Yamaguchi M (1994) Histomorphological confirmation of the preventive effect of beta-alanyl-L-histidinato zinc on bone loss in ovariectomized rats. Biol Pharm Bull 17: 862-865.

50. Yamaguchi M, Uchiyama S (2003) Preventive effect of zinc acexamate administration in streptozotocin-diabetic rats: Restoration of bone loss. Int $J$ Mol Med 12: 755-761.

51. Uchiyama S, Yamaguchi M (2003) Alteration in serum and bone componen findings induced in streptozotocin-diabetic rats is restored by zinc acexamate. Int J Mol Med 12: 949-954

52. Yamaguchi M, Gao YH (1998) Anabolic effect of genistein and genistin on bone metabolism in the femoral-metaphyseal tissues of elderly rats: the genistein effect is enhanced by zinc. Mol Cell Biochem 178: 377-382.

53. Kuiper GG, Lemmen JG, Carlsson B, Corton JC, Safe SH, et al. (1998) Interaction of estrogenic chemicals and phytoestrogens with estrogen recepto beta. Endocrinology 139: 4252-4263.

54. Gao YH, Yamaguchi M (1999) Anabolic effect of daidzein on cortical bone in tissue culture: comparison with genistein effect. Mol Cell Biochem 194: 93-97.

55. Sugimoto E, Yamaguchi M (2000) Anabolic effect of genistein in osteoblastic MC3T3-E1 cells. Int J Mol Med 5: 515-520.

56. Sugimoto E, Yamaguchi M (2000) Stimulatory effect of Daidzein in osteoblastic MC3T3-E1 cells. Biochem Pharmacol 59: 471-475.

57. Yamaguchi M, Sugimoto $E$ (2000) Stimulatory effect of genistein and daidzein on protein synthesis in osteoblastic MC3T3-E1 cells: activation of aminoacyltRNA synthetase. Mol Cell Biochem 214: 97-102.

58. Yamaguchi M, Weitzmann MN (2009) The estrogen 17beta-estradiol and phytoestrogen genistein mediate differential effects on osteoblastic NF-kappaB activity. Int J Mol Med 23: 297-301.

59. Yamaguchi M, Gao YH (1998) Inhibitory effect of genistein on bone resorption in tissue culture. Biochem Pharmacol 55: 71-76.

60. Gao YH, Yamaguchi M (1999) Inhibitory effect of genistein on osteoclast-like cell formation in mouse marrow cultures. Biochem Pharmacol 58: 767-772.

61. Gao YH, Yamaguchi M (1999) Suppressive effect of genistein on rat bone osteoclasts: apoptosis is induced through $\mathrm{Ca}^{2+}$ signaling. Biol Pharm Bull 22 805-809.

2. Gao YH, Yamaguchi M (2000) Suppressive effect of genistein on rat bone osteoclasts: involvement of protein kinase inhibition and protein tyrosine phosphatase activation. Int J Mol Med 5: 261-267.

63. Missbach M, Jeschke M, Feyen J, Müller K, Glatt M, et al. (1999) A nove inhibitor of the tyrosine kinase Src suppresses phosphorylation of its majo cellular substrates and reduces bone resorption in vitro and in rodent models in vivo. Bone 24: 437-449.

64. Gao YH, Yamaguchi M (1998) Zinc enhancement of genistein's anabolic effect on bone components in elderly female rats. Gen Pharmacol 31: 199-202.

65. Yamaguchi M, Gao YH, Ma ZJ (2000) Synergistic effect of genistein and zinc on bone components in the femoral-metaphyseal tissues of female rats. J Bone Miner Metab 18: 77-83

66. Ma ZJ, Igarashi A, Inagaki M, Mitsugi F, Yamaguchi M (2000) Supplemental intake of isoflavones and zinc-containing mineral mixture enhances bone components in the femoral tissues of rats with increasing age. J Health Sci 46: 363-369.

67. Uchiyama S, Yamaguchi M (2007) Genistein and zinc synergistically enhance gene expression and mineralization in osteoblastic MC3T3-E1 cells. Int J Mo Med 19: 213-220. 
68. Yohay DA, Zhang J, Thrailkill KM, Arthur JM, Quarles LD (1994) Role of serum in the developmental expression of alkaline phosphatase in MC3T3-E1 osteoblasts. J Cell Physiol 158: 467-475

69. Lian JB, Stein GS, Cannalis E, Roky PG, Boskey AL (1999) Bone formation: Osteoblast lineage cells, growth factor, matrix protein, and the mineralization process. ( $4^{\text {th }}$ edition)Primer on the Metabolic Bone Disease and Disorders of Mineral Metabolism, New York, Lippincott Williams \& Wilkins Press.

70. Uchiyama S, Yamaguchi M (2007) Genistein and zinc synergistically stimulate apoptotic cell death and suppress RANKL signaling-related gene expression in osteoclastic cells. J Cell Biochem 101: 529-542.

71. Ma ZJ, Shimanuki S, Igarashi A, Kawasaki Y, Yamaguchi M (2000) Preventive effect of dietary fermented soybean on bone loss in ovariectomized rats: Enhancement with isoflavone and zinc supplementation. J Health Sci 46: 263 268 .

72. Yamaguchi M, Igarashi A, Sakai M, Degawa H, Ozawa Y (2005) Prolonged intake of dietary fermented isoflavone-rich soybean reinforced with zinc affects circulating bone biochemical markers in aged individuals. J Health Sci 51: 191196.

73. Price PA (1985) Vitamin K-dependent formation of bone Gla protein (osteocalcin) and its function. Vitam Horm 42: 65-108.

74. Hara K, Akiyama Y, Nakamura T, Murota S, Morita I (1995) The inhibitory effect of vitamin K2 (menatetrenone) on bone resorption may be related to its side chain. Bone 16: 179-184.

75. Hosoi T (1996) [Recent progress in treatment of osteoporosis]. Nihon Ronen Igakkai Zasshi 33: 240-244.

76. Schurgers LJ, Teunissen KJ, Hamulyák K, Knapen MH, Vik H, et al. (2007) Vitamin K-containing dietary supplements: comparison of synthetic vitamin K1 and natto-derived menaquinone-7. Blood 109: 3279-3283.

77. Shearer MJ (2000) Role of vitamin K and Gla proteins in the pathophysiology of osteoporosis and vascular calcification. Curr Opin Clin Nutr Metab Care 3: 433-438.

78. Delmas PD (1993) Biochemical markers of bone turnover. I: Theoretica considerations and clinical use in osteoporosis. Am J Med 95: 11S-16S.

79. van Summeren MJ, Braam LA, Lilien MR, Schurgers LJ, Kuis W, et al. (2009) The effect of menaquinone-7 (vitamin K2) supplementation on osteocalcin carboxylation in healthy prepubertal children. Br J Nutr 102: 1171-1178.

80. Hodges SJ, Akesson K, Vergnaud P, Obrant K, Delmas PD (1993) Circulating levels of vitamins $\mathrm{K} 1$ and $\mathrm{K} 2$ decreased in elderly women with hip fracture. $J$ Bone Miner Res 8: 1241-1245.

81. Binkley NC, Krueger DC, Engelke JA, Foley AL, Suttie JW (2000) Vitamin K supplementation reduces serum concentrations of under-gamma-carboxylated osteocalcin in healthy young and elderly adults. Am J Clin Nutr 72: 1523-1528.

82. Schurgers LJ, Vermeer C (2000) Determination of phylloquinone and menaquinones in food. Effect of food matrix on circulating vitamin $K$ concentrations. Haemostasis 30: 298-307.

83. Shearer MJ (2009) Vitamin K in parenteral nutrition. Gastroenterology 137 S105-118.

84. Ehara Y, Takahashi H, Hanahisa Y, Yamaguchi M (1996) Effect of vitamin $\mathrm{K}^{2}$ (menaquinone-7) on bone metabolism in the femoral-metaphyseal tissues of normal and skeletal-unloaded rats: enhancement with zinc. Res Exp Med (Berl) 196: $171-178$

85. Yamaguchi M, Uchiyama S, Tsukamoto $Y$ (2002) Stimulatory effect of menaquinone-7 on bone formation in elderly female rat femoral tissues in vitro: prevention of bone deterioration with aging. Int J Mol Med 10: 729-733.

86. Yamaguchi M, Sugimoto E, Hachiya S (2001) Stimulatory effect of menaquinone-7 (vitamin $\mathrm{K}_{2}$ ) on osteoblastic bone formation in vitro. Mol Cell Biochem 223: 131-137.

87. Yamaguchi M, Ma ZJ (2001) Inhibitory effect of menaquinone-7 (vitamin $\mathrm{K}_{2}$ ) on osteoclast-like cell formation and osteoclastic bone resorption in rat bone tissues in vitro. Mol Cell Biochem 228: 39-47.

88. Yamaguchi M, Weitzmann MN (2011) Vitamin $\mathrm{K}_{2}$ stimulates osteoblastogenesis and suppresses osteoclastogenesis by suppressing NF-kB activation. Int J Mol Med 27: 3-14.

89. Tabb MM, Sun A, Zhou C, Grün F, Errandi J, et al. (2003) Vitamin $\mathrm{K}_{2}$ regulation of bone homeostasis is mediated by the steroid and xenobiotic receptor SXR. J Biol Chem 278: 43919-43927.

90. Yamaguchi M, Taguchi H, Gao YH, Igarashi A, Tsukamoto Y (1999) Effect of vitamin $\mathrm{K}_{2}$ (menaquinone-7) in fermented soybean (natto) on bone loss in ovariectomized rats. J Bone Miner Metab 17: 23-29.

91. Yamaguchi M, Kakuda H, Gao YH, Tsukamoto Y (2000) Prolonged intake of fermented soybean (natto) diets containing vitamin $\mathrm{K}_{2}$ (menaquinone-7) prevents bone loss in ovariectomized rats. J Bone Miner Metab 18: 71-76.

92. Tsukamoto $Y$, Ichise $H$, Yamaguchi M (2000) Prolonged intake of dietary fermented soybeans (natto) with the reinforced vitamin $\mathrm{K}_{2}$ (menaquinone-7) enhances circulating ?-carboxylated osteocalcin concentration in normal individuals. J Health Sci 46: 317-321.

93. Tsukamoto $Y$, Ichise $H$, Kakuda $H$, Yamaguchi $M(2000)$ Intake of fermented soybean (natto) increases circulating vitamin $\mathrm{K}_{2}$ (menaquinone-7) and gammacarboxylated osteocalcin concentration in normal individuals. J Bone Miner Metab 18: 216-222.

94. Knapen MH, Drummen NE, Smit E, Vermeer C, Theuwissen E (2013) Threeyear low-dose menaquinone-7 supplementation helps decrease bone loss in healthy postmenopausal women. Osteoporos Int 24: 2499-2507.

95. Ma ZJ, Igarashi A, Yamakawa K, Yamaguchi M (2001) Enhancing effect of zinc and vitamin $\mathrm{K}_{2}$ (menaquinone-7) on bone components in the femoral tissues of female elderly rats. J Health Sci 47: 40-45.

96. Adams JS, Hewison M (2010) Update in vitamin D. J Clin Endocrinol Metab 95: 471-478.

97. Bikle DD (2010) Vitamin D: newly discovered actions require reconsideration of physiologic requirements. Trends Endocrinol Metab 21: 375-384.

98. Khazai N, Judd SE, Tangpricha V (2008) Calcium and vitamin D: skeletal and extraskeletal health. Curr Rheumatol Rep 10: 110-117

99. Merlino LA, Curtis J, Mikuls TR, Cerhan JR, Criswell LA, et al. (2004) Vitamin $D$ intake is inversely associated with rheumatoid arthritis: results from the lowa Women's Health Study. Arthritis Rheum 50: 72-77.

100. Ardizzone S, Cassinotti A, Bevilacqua M, Clerici M, Porro GB (2011) Vitamin D and inflammatory bowel disease. Vitam Horm 86: 367-377.

101.Bischoff-Ferrari HA, Willett WC, Wong JB, Stuck AE, Staehelin HB, et al. (2009) Prevention of nonvertebral fractures with oral vitamin $D$ and dose dependency: a meta-analysis of randomized controlled trials. Arch Intern Med 169: 551-561.

102. Björkman M, Sorva A, Risteli J, Tilvis R (2008) Vitamin D supplementation has minor effects on parathyroid hormone and bone turnover markers in vitamin D-deficient bedridden older patients. Age Ageing 37: 25-31.

103. Viljakainen HT, Väisänen M, Kemi V, Rikkonen T, Kröger H, et al. (2009) Wintertime vitamin $\mathrm{D}$ supplementation inhibits seasonal variation of calcitropic hormones and maintains bone turnover in healthy men. J Bone Miner Res 24 346-352.

104.von Hurst PR, Stonehouse W, Kruger MC, Coad J (2010) Vitamin D supplementation suppresses age-induced bone turnover in older women who are vitamin D deficient. J Steroid Biochem Mol Biol 121: 293-296.

105. Yamaguchi M, Sakashita $T$ (1986) Enhancement of vitamin $D_{3}$ effect on bone metabolism in weanling rats orally administered zinc sulphate. Acta Endocrinol (Copenh) 111: 285-288.

106. Yamaguchi M, Ozaki K, Suketa Y (1989) Alteration in bone metabolism with increasing age: effects of zinc and vitamin $D_{3}$ in aged rats. J Pharmaco-Dyn 12: $67-73$.

107.Yamaguchi M, Inamoto K (1986) Differential effects of calcium-regulating hormones on bone metabolism in weanling rats orally administered zinc sulfate. Metabolism 35: 1044-1047.

108. Yamaguchi $M$, Oishi $H$ (1989) Effect of 1,25-dihydroxyvitamin $D_{3}$ on bone metabolism in tissue culture. Enhancement of the steroid effect by zinc. Biochem Pharmacol 38: 3453-3459.

109. McDonnell DP, Mangelsdorf DJ, Pike JW, Haussler MR, O'Malley BW (1987) Molecular cloning of complementary DNA encoding the avian receptor for vitamin D. Science 235: 1214-1217. 